\title{
Association of low Serum Magnesium level with occurrence of Ventricular Arrhythmia in patients with Acute Myocardial Infarction
}

\author{
Nizam Uddin ${ }^{1}$, Abdul Wadud Chowdhury², Mohsin Ahmed ${ }^{3}$, MD Khalequzzaman ${ }^{4}$, Gaffer Amin $^{5}$, \\ Gias uddin Salim ${ }^{6}$, ABM Imam Hossain ${ }^{7}$
}

\begin{abstract}
:
Background: Acute Myocardial Infarction is the leading cause of morbidity and mortality throughout the world. Its prevalence among developing countries has increased significantly over the past two decades. Acute myocardial infarction is associated with electrolyte imbalance most commonly hypomagnesemia and hypokalaemia. Both are associated with ventricular arrhythmia which can lead to increase hospital mortality and morbidity.

Objectives: To find out association of hypomagnesemia with ventricular arrhythmia in patients with acute myocardial infarction.

Methods: Patients with acute myocardial infarction admitted in the department of Cardiology, $\mathrm{DMCH}$, within the study period and who fulfilled the inclusion and exclusion criteria were taken as study sample. Informed consent was taken from all patients and then the patients were evaluated by detailed history, clinical examination and relevant investigations. Serum magnesium level was measured after admission. The sample population was Grouped into Group A(Acute myocardial infarction with normal serum magnesium) and Group B(Acute myocardial infarction with hypomagnesemia). Patients were followed up regularly till discharge or death for evidence of ventricular arrhythmia. Then the obtained data was analysed with SPSS 22.0.

Results: Among 110 patients of Acute MI, 44 patients were in Group A who had plasma magnesium level e" $0.7 \mathrm{mmol} /$ I and 66 patients were in Group B who had plasma magnesium level $<0.7 \mathrm{mmol} / \mathrm{l}$. Incidence of hypoagnesemia
\end{abstract}

was $60 \%$ and more common in male. Male vs female percentage of hypomagnesemia were $61 \%$ vs $39 \%$. Mean age was $54.16 \pm 11.72$ yrs vs $57.52 \pm 10.59$ yrs in group A vs group $B$. On admission serum magnesium level was 0.9218 vs $0.523 \mathrm{mmol} / \mathrm{L}$ ( group A vs group B). The study showed that group $B$ patients were more haemodynamically unstable and mean SBP and DBP were found 89.39 \pm 19.93 and $60.67 \pm 11.56 \mathrm{~mm}-\mathrm{Hg}$ respectively. Troponin I was markedly increased in group $B$ than $A$ (i.e $4.7 \pm 1.79$ vs $14.6 \pm 4.3 \mathrm{vs} \mathrm{ng} / \mathrm{ml}$ ). Adverse cardiac events such as cardiogenic shock (group A vs group B $=11.36 \%$ vs $28.27 \%$ ) and ventricular arrhythmias(group $A$ vs group $B=34 \%$ vs $72.73 \%$ ) were also higher in group $B$ than group $A$. Mean hospital stay for group B patient was higher than group $A(6.78 \pm 0.85$ vs $5.31 \pm 0.35$ days). The study result showed that ventricular arrhythmia is negatively correlated with serum magnesium and the correlation coefficient was 0.541 . It also showed that serum Magnesium is positively correlated with Potassium( $r=0.831, p<0.01)$ and Calcium( $r=$ $0.902, p<0.001)$. Multiple logistic regression analysis showed that hypomagnesemia is an independent risk factor for ventricular arrhythmia.

Conclusions: This study showed that in patients with acute myocardial infarction, hypomagnesemia is common and it is significantly associated with ventricular arrhythmia. So the presence of hypomagnesemia should alert the physicians to adopt corrective measures as it increases both mortality and morbidity.

Keywords: Hypomagnesemia, Ventricular Arrythmia, Acute myocardial infarction.

(Bangladesh Heart Journal 2020; 35(1): 39-46)

1. Registrar, Department of Cardiology, Dhaka Medical College Hospital, Dhaka, Bangladesh.

2. Professor and Head of Department Cardiology, Dhaka Medical College, Dhaka, Bangladesh.

3. Associate Professor, Department of Cardiology, National institute of cardiovascular Disease, Dhaka. Bangladesh.

4. Associate Professor, Department of Cardiology, Dhaka Medical college, Dhaka, Bangladesh.

5. Assistant professor, Department of Cardiology, Dhaka Medical college, Dhaka, Bangladesh

6. Indoor Medical Officer, Department of cardiology, Dhaka Medical College hospital. Dhaka

7. Junior Consultant (Cardiology), Sadar Hospital, Jhalakathi, Bangladesh.

Address of Correspondence: Dr Mohammed Nizam Uddin, Registrar, Department of Cardiology, Dhaka Medical College Hospital, Dhaka, Bangladesh. Mobile: 01937206117, email: nizammozumder@gmail.com

DOI: https://doi.org/10.3329/bhj.v35i1.49141

Copyright $\odot 2017$ Bangladesh Cardiac Society. Published by Bangladesh Cardiac Society. This is an Open Access articles published under the Creative Commons Attribution-NonCommercial 4.0 International License (CC BY-NC). This license permits use, distribution and reproduction in any medium, provided the original work is properly cited and is not used for commercial purposes. 


\section{Introduction:}

Myocardial infarction (MI) can be recognised by clinical features, including electrocardiographic (ECG) findings, elevated values of biochemical markers (biomarkers) of myocardial necrosis, and by imaging, or may be defined by pathology. It is a major cause of death and disability worldwide ${ }^{1}$. New ST elevation at $\mathrm{J}$ point in two contiguous leads with cut-points: e" $1 \mathrm{~mm}$ in all leads other than leads V2-V3 where the following cut points apply: e" $2 \mathrm{~mm}$ in men e"40 years; e"2.5mm in men <40 years or e" $1.5 \mathrm{~mm}$ in women ${ }^{1}$.

Acute myocardial infarction is associated with electrolyte imbalance most commonly hypomagnesemia and hypokalaemia. Both are associated with ventricular arrhythmia which can lead to increase hospital mortality and morbidity ${ }^{2}$.

Magnesium is the $2^{\text {nd }}$ most common intracellular cation after potassium and $4^{\text {th }}$ abundant cation in the body. The total magnesium content in the body of an average adult is around $25 \mathrm{Gm}$ or $1000 \mathrm{mmol}$. About $60 \%$ of the body reserve of magnesium is found in the skeletal bone mass, about $20 \%$ is in muscle and another $20 \%$ is in soft tissues and liver. Normal plasma Magnesium concentration is from 1.7 to $2.5 \mathrm{mg} / \mathrm{dl}^{3}$.

Hypomagnesaemia is present in acute myocardial infarction (AMI) as shift of magnesium from extra cellular to intracellular compartments occur as it is taken up by adipocytes after catecholamine induced lipolysis and combined with soaps formed by free fatty acids ${ }^{4,5}$. Although the total body Mg contents may not change with the onset of AMI, extra cellular Mg declines markedly, especially over the first 24 to 48 hours after the onset of $\mathrm{AMI}^{5,7}$. Hypomagnesaemia in the initial phase of post AMI period is very critical, as ventricular tachyarrhythmia sudden cardiac death and re-infarction are the usual outcome. 4,5,6 Magnesium has been suggested as a possible intervention to be used in AMI since the early 1960s mainly because it was thought to be an antiarrhythmic agent, although no studies have conclusively shown this to be the mechanism of action for magnesium in reducing mortality. ${ }^{6}$

Magnesium, a divalent cation, is a physiologic calcium antagonist that inhibits calcium entry into vascular smooth muscle cells. ${ }^{12,13}$ Furthermore, magnesium promotes coronary artery vasodilation and peripheral systemic arterial vasodilation, thereby increasing coronary blood flow and reducing afterload. ${ }^{14,15}$ Magnesium may reduce ischemia and decrease sinus node and atrioventricular conduction. ${ }^{16}$ Because of its ability to inhibit myocardial cell sodium and calcium influx as well as potassium egress, magnesium may diminish infarct related reperfusion injury and myocardial stunning, thereby limiting infarct size. ${ }^{17}$

\section{Methods:}

Prospective cross sectional study was conducted in the Department of Cardiology, DMCH, Dhaka, Bangladesh from January 2017 to Dec 2017. All the patients with Acute Myocardial infarction with or without hypomagnesaemia admitted in the department of Cardiology, $\mathrm{DMCH}$, within the study period and who fulfilled the other inclusion and exclusion criteria was taken as sample.

\section{Inclusion criteria:}

All the Acute Myocardial infarction patients with or without hypomagnesemia presenting to $\mathrm{CCU}$ in $\mathrm{DMCH}$ within the study period. Acute coronary syndrome was included STEMI, non-STMI.

\section{Exclusion criteria:}

- Patients with history of any previous MI.

- Patients with history of PCI or CABG.

- Patients with any valvular heart disease, congenital heart disease, primary myocardial or pericardial disease, acute on chronic heart failure

- Patients with other co-morbid .conditions like COPD, end stage renal disease, nephrotic syndrome, liver disease, chest infection and bronchogenic carcinoma, stroke, hypothyroidism

- Post diarrhea MI(within last 3 days)

- Patients on Total parenteral nutrition

- Patients unwilling to give consent.

\section{Ethical Consideration:}

Prior to the commencement of this study, the research protocol was approved by the Research Review Committee of Department of Cardiology and the Ethical Review Committee of DMCH, Dhaka. The aims and objective of the study along with its procedure, alternative diagnostic methods, risk and benefits was explained to the patients in easily understandable local language and then informed consent will be taken from each patient. It was assured that all records was kept confidential and the procedure will be helpful for both the physician and patients in making rational approach regarding management of the case.

\section{Statistical Analysis:}

All statistical analysis was performed using the statistical package for social science ( SPSS ) program, version 22 for Windows. Continuous parameters was expressed as mean $\pm S D$ and categorical parameters as frequency and percentage. Comparisons between groups 
(continuous parameters) was done by Student's t test. Categorical parameters was compared by Chi-Square test. Correlation analyses was done by Pearson correlation coefficient. The significance of the results as determined in $95.0 \%$ confidence interval and a value of $p$ $<0.05$ was considerd statistically significant.

\section{Methods of Data Collection:}

All patients of Acute Myocardial infarction admitted in the department of cardiology, Dhaka Medical college hospital within the study period who fulfilled the inclusion and exclusion criteria was taken as sample. Information from the patients and relatives were collected through preformed proforma. Patients were evaluated based upon History, Clinical examination and investigations. After Admission Serum magnesium level was done concurrently Serum calcium, Serum potassium was done to exclude other confounding variables, Cardiac biomarkers were done to differentiate between STEMI, NSTEMI. Occurrence of Ventricular arrhythmia were counted on repeated regular ECG tracing on twice daily when admission in Hospital. Then occurrence of Ventricular arrhythmia of Acute Myocardial infarction patients with hypomagnesaemia and those without hypomagnesaemia were compared and analyzed. After compilation of collected data collection from all patients, statistical analysis were performed using the statistical package for social science( SPSS ) program, version 22 for Windows. The confidentiality of the patient was maintained properly when observations were compiled by the investigator. Informed written consent were taken from each patient. Continuous parameters was expressed as mean $\pm S D$ and categorical parameters as frequency and percentage. Study subjects were grouped into 2 groups, patients with hypomagnesemia (Plasma magnesium level $<0.7 \mathrm{mmol} / \mathrm{L}$ as Group B and patients with normal plasma magnesium level e"0.7 mmol/L as Group A. Comparisons between groups (continuous parameters) was done by Student's t test. Categorical parameters was compared by Chi-Square test. Correlation analyses was done by Pearson correlation coefficient. The significance of the results as determined in $95.0 \%$ confidence interval and a value of $p<0.05$ was considered statistically significant.

\section{Result :}

This prospective observational study was conducted in the Department of Cardiology, Dhaka Medical College Hospital, Dhaka, over a period of one year from Jan 2017 to Dec 2017. The main objective of the study was to find out the association between low serum magnesium and ventricular arrythmia in patients with acute myocardial infarction. A total of 110 adult patients with acute myocardial infarction(both STEMI and NSTEMI) admitted in the department of cardiology, $\mathrm{DMCH}$ within the study period were included in the study. The study population was divided into two groups: Group A included AMI with normal serum magnesium level (e"0.7 mmol/dl) and Group B included AMI with low serum magnesium level ( $<0.7 \mathrm{mmol} /$ dl). These patients were followed up during hospital stay to evaluate the prelevance of different types of ventricular arrhythmia( Frequent PVC, Idioventricular rhythm, Sustained VT, non sustained VT, VF). Appropriate statistical techniques were used for data analysis. Results were presented with tables and graphs where required.

Table-I

Distribution of study subjects by age $(n=110)$

\begin{tabular}{lccccc}
\hline Age in years & \multicolumn{2}{c}{$\begin{array}{c}\text { Group A } \\
(n=44)\end{array}$} & \multicolumn{2}{c}{$\begin{array}{c}\text { Group B } \\
(n=66)\end{array}$} & P value \\
& No. & $\%$ & No. & $\%$ & \\
\hline $31-40$ & 9 & 20.45 & 7 & 10.61 & \\
$41-50$ & 7 & 16 & 10 & 15.15 & \\
$51-60$ & 15 & 34 & 15 & 22.73 & \\
$61-70>70$ & 84 & 18.1811 .37 & 277 & 40.9110 .6 & \\
Total & 44 & 100.0 & 66 & 100.0 & \\
Mean $\pm S D$ & $54.16 \pm 11.70$ & $58.45 \pm 9.47$ & $<0.066^{n s}$ \\
(Range mgm) & $(42-66)$ & \multicolumn{2}{c}{$(46-68)$} & \\
\hline
\end{tabular}

$P$ value reached from unpaired t-test.

Group A: Acute myocardial infarction patients with normal serum magnesium

Group B: Acute myocardial infarction patients with hypomagnesemia

ns: not significant

Above table shows the age distribution of study subjects. It shows that maximum patients of Group $A$ is in the age group of 51-60 yrs 15(34\%) whereas maximum (27 or $40.91 \%$ ) in Group B is in $61-70$ yrs. The mean age is $54.16 \pm 11.70$ (yrs) vs $58.45 \pm 9.47$ (yrs) in Group A vs B. The mean difference between two Groups were statistically not significant $(p<0.05)$.

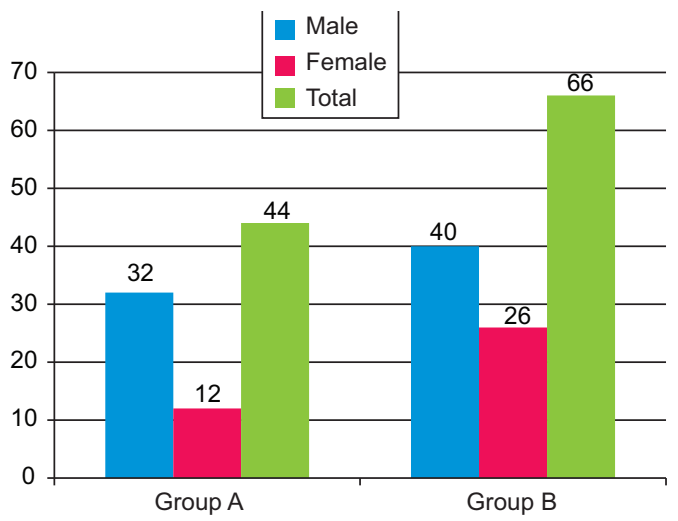

Fig.-1: Bar diagram showing distribution of the sex between two groups $(n=110)$

Fig.1: Bar diagram showing distribution of the sex between two groups. It shows Male is $32(72.7 \%)$ vs 
Table-II

Comparison of biochemical parameters between two groups $(n=110)$

\begin{tabular}{lccc}
\hline Laboratory parameters & $\begin{array}{c}\text { Group A(n=44) } \\
\text { Mena } \pm \text { SD }\end{array}$ & $\begin{array}{c}\text { Group B(n=66) } \\
\text { Mena } \pm S D\end{array}$ & P value \\
\hline Troponin- I $(\mathrm{ng} / \mathrm{ml})$ & $4.7 \pm 1.79$ & $14.87 \pm 4.3$ & $0.001^{\mathrm{s}}$ \\
Serum creatinine $(\mathrm{mg} / \mathrm{dl})$ & $0.807 \pm 0.168$ & $0.92 \pm 0.185$ & $0.511^{\mathrm{ns}}$ \\
Serum Potassium $(\mathrm{mmol} / \mathrm{l})$ & $3.84 \pm 0.16$ & $2.54 \pm 0.41$ & $0.001^{\mathrm{s}}$ \\
Serum Calcium $(\mathrm{mg} / \mathrm{dl})$ & $8.71 \pm 0.3$ & $6.52 \pm 0.55$ & $0.001^{\mathrm{s}}$ \\
\hline
\end{tabular}

Data were expressed as mean \pm SD

$P$ value reached from unpaired t-test.

Group A : Acute myocardial infarction with normal Serum magnesium

Group B : Acute myocardial infarction with hypomagnesemia

ns $\quad$ : not significant

s : : significant

$\mathrm{n} \quad$ : number of patients

Table-III

Comparison of in-hospital adverse cardiac events between the study groups $(n=110)$

\begin{tabular}{|c|c|c|c|c|c|}
\hline \multirow[t]{2}{*}{ Adverse cardiac events } & \multicolumn{2}{|c|}{ Group A $(n=44)$} & \multicolumn{2}{|c|}{ Group B $(n=66)$} & \multirow[t]{2}{*}{ Pvalue } \\
\hline & $\mathrm{N}$ & $\%$ & $\mathrm{~N}$ & $\%$ & \\
\hline \multicolumn{6}{|l|}{ Cardiogenic shock } \\
\hline Yes & 05 & 11.36 & 18 & 27.27 & \multirow[t]{2}{*}{$0.044^{\mathrm{s}}$} \\
\hline No & 39 & 88.66 & 48 & 72.73 & \\
\hline \multicolumn{6}{|l|}{ Asystole } \\
\hline Yes & 04 & 9.09 & 08 & 12.13 & \multirow[t]{2}{*}{$0.6195^{\mathrm{NS}}$} \\
\hline No & 40 & 90.91 & 58 & 87.87 & \\
\hline \multicolumn{6}{|l|}{ Ventricular Arrhythmia } \\
\hline Yes & 15 & 34.1 & 48 & 72.73 & \multirow[t]{2}{*}{$0.001^{\mathrm{s}}$} \\
\hline No & 29 & 65.90 & 18 & 27.27 & \\
\hline \multicolumn{6}{|l|}{ Post Ml angina } \\
\hline Yes & 10 & 22.72 & 10 & 15.15 & \multirow[t]{2}{*}{$0.3129^{\mathrm{ns}}$} \\
\hline No & 34 & 77.28 & 56 & 84.85 & \\
\hline \multicolumn{6}{|l|}{ Death } \\
\hline Yes & 01 & 2.27 & 06 & 9.09 & \multirow[t]{2}{*}{$0.1512^{\mathrm{ns}}$} \\
\hline No & 43 & 97.73 & 66 & 90.91 & \\
\hline
\end{tabular}

$P$ value reached from unpaired t-test.

Group A

:Acute myocardial infarction with normal Serum magnesium

Group B

$\mathrm{s}=$ significant:

ns=not significant

40(60.6\%) respectively in Group A vs Group B, Similarly Female is $12(27.3 \%)$ vs $26(39.3 \%)$ respectively in Group A and Group B. It shows, the difference between this two groups is not statistically significant $(p<0.05)$

Above table shows that mean troponin I is $4.7 \pm 1.79$ vs $14.87 \pm 4.3(\mathrm{ng} / \mathrm{dl})$ respectively in group $A$ vs group $B$. Serum creatinine is $0.807 \pm 0.168$ vs $0.92 \pm 0.185$ respectively in group $A$ vs group $B$. Serum Potassium is $3.84 \pm 0.16$ vs $2.54 \pm 0.41$ respectively in group $A$ vs group
B. Serum Calcium is $8.71 \pm 0.3$ vs $6.52 \pm 0.55$ respectively in group A vs group B. The mean difference of troponin I, serum Potassium, Calcium between group $A$ and group $B$ is statistically significant $(p<0.05)$ but mean serum creatinine between this two groups is not statistically significant $(P>0.05)$.

Table shows the distribution of adverse cardiac events namely cardiogenic shock, asystole, ventricular arrhythmia, post MI angina and Death. It shows that 
Ventricular arrhythmia and Cardiogenic shock between group $A$ and $B$ is statistically significant $(P<0.05)$ whereas Post $\mathrm{Ml}$ angina, asystole and Death between group $\mathrm{A}$ and $B$ are not statistically significant $(p>0.05)$.

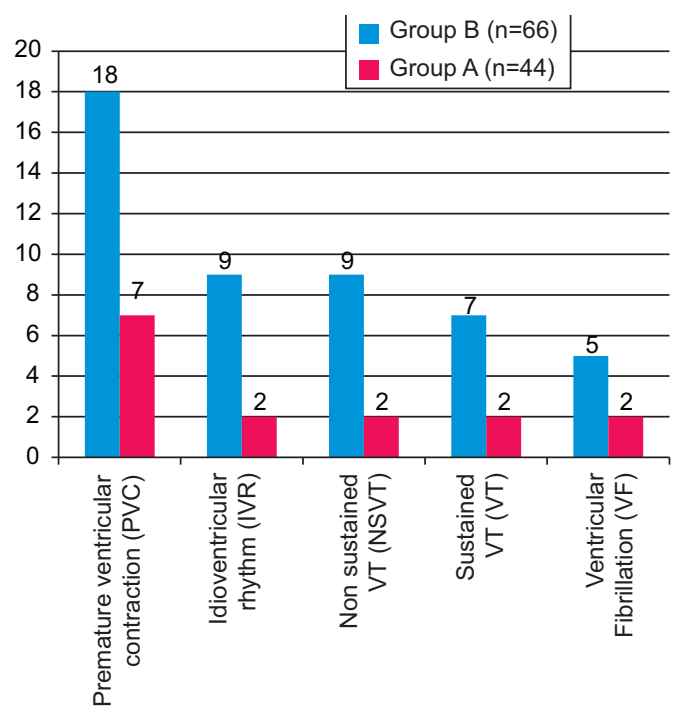

Fig.-2: Bar Graph Showing Frequency distribution of Ventricular Arrythmia in Between Group ( $n=110) s$

The figure shows that premature ventricular contraction(PVC) is most frequent arrhythmia in both group - 7 (46.66\%) vs $18(39 \%)$ respectively in group A vs Group B. Group B has more incidence of Ventricular Arrhythmia than group A, respectively $48(72.72 \%)$ vs $15(34.09 \%)$. This difference between two groups is statistically significant $(p<0.05)$.

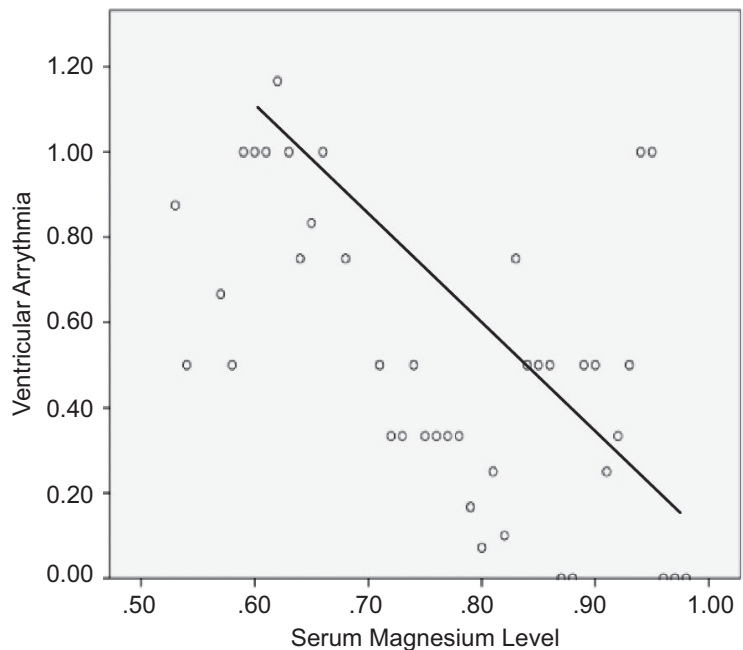

Fig.-3: Showing correlation between serum magnesium level with occurrence of ventricular arrhythmia in Group $B(n=66)$

The scattered diagram shows corerelation between ventricular arrhythmia and serum magnesium level. It shows serum magnesium level is negatively correlated with ventricular arrhythmia with correlation co efficient ${ }^{\circledR}-.541$

Table-IV

Correlation between Ventricular arrhythmia and other Biochemical parameters

\begin{tabular}{lcc}
\hline & $\mathrm{R}$ & $\mathrm{p}$-value \\
\hline S. Magnesium & -0.541 & $<0.001^{\mathrm{s}}$ \\
S. Potassium & -0.436 & $0.010^{\mathrm{s}}$ \\
S. Calcium & -0.530 & $<0.001^{\mathrm{s}}$ \\
\hline
\end{tabular}

$r=$ Pearson's correlation co-efficient.

$s=$ significant $(p<0.05)$.

Table-V

Multivariate Logistic regression analysis of Ventricular arrhythmia with independent risk factors in patients with Acute Myocardial Infarction

\begin{tabular}{lcccccc}
\hline Independent risk factors & B & S.E. & P value & Odd ratio & \multicolumn{2}{c}{ 95\% C.I. for EXP(B) } \\
\cline { 6 - 7 } & & & & & Lower & Upper \\
\hline Obesity & -0.140 & 0.128 & 0.275 & 1.00 & -0.485 & 0.007 \\
Sytolic BP & -0.16 & 0.03 & 2.07 & 0.493 & -0.011 & 0.01 \\
Diastolic BP & -0.09 & 0.06 & & 1 & 2.6 .0 & -0.003 \\
$\quad-0.02$ & -0.159 & 0.05 & 0.06 & 2 & -0.281 & -0.064 \\
Heart failure & 0.02 & 0.106 & 0.79 & 0.723 & -0.174 & 0.25 \\
Cardiogenic shock & 0.023 & 0.015 & 0.14 & 0.971 & .932 & 1.010 \\
Troponin I ng/ml & -0.067 & 0.044 & 0.87 & 1.066 & .974 & 1.167 \\
Hospital stay & -0.020 & 0.196 & 0.307 & 8.388 & 1.268 & 55.48 \\
S. Potassium & -0.2 & 0.5 & 0.456 & 1 & -0.33 & 0.2 \\
S. Calcium & 16.380 & 5.90 & 0.001 & 136 & 136 & 1381 \\
S. Magnesium & & & & & & \\
\hline
\end{tabular}


This table shows that there is a significant negative correlation between ventricular arrhythmia with serum magnesium $(r=-0.541, p<0.001)$, serum potassium $(r=-$ $.436, p<0.01)$, serum calcium $(r=-0.530, p<0.001)$. It also shows Serum magnesium is negatively correlated with serum calcium and serum potassium.

Table V: shows logistic regression analysis of Ventricular arrhythmia with independent risk factors. Out of 10 variables, only hypomagnesemia was observed as independent risk factor (OR-136,p-0.001), Other 9 variables such as Obesity, Systolic BP, Diastolic BP, Cardiogenic shock, Troponin I, Hospital stay, Serum potassium, Serum calcium and Heart Failure, none was observed as independent predictors for developing ventricular arrhythmia (OR-1,p-0.275; 2.07,0.493; 263,0.1; $2,0.06 ; 0.7,0.73 ; 0.9,0.14 ; 8.38,0.3 ; 1,0.456)$.

\section{Discussion:}

This prospective comparative observational study was conducted in the coronary care unit (CCU) of Department of Cardiology, Dhaka Medical College Hospital, Dhaka, over a period of one year from Jan 2017 to Dec 2017. The main objective of the study was to find out the association of ventricular arrhythmia with low serum magnesium in patient with acute myocardial infarction admitted in Dhaka Medical College Hospital during this time period.

For this purpose 110 newly diagnosed acute myocardial infarction patients were included according to exclusion and inclusion criteria. The study population was divided into two groups based on serum magnesium level. Those with Acute Myocardial infarction with normal magneseium was in Group A which includes 44 patients. In group B, 66 patient were included those with acute myocardial infarction with hypomagnesemia.

It was found that hypomagnesemia occurs in $86.66 \%$ in acute myocardial infarction ${ }^{18}$, similar study found Hiralal Murmu ${ }^{19}$ and it was $80 \%$ whereas our study showed it was around $60 \%(66)$. In our study male were more common in both group. It observed that age(years) incidence was $54.16 \pm 11.70 \mathrm{yrs}$ and $58.45 \pm 9.47 \mathrm{yrs}$ in between group $A$ and group $B$ respectively .

Our study showed male have higher incidence of hypomagnesemia $40(60.60 \%)$ vs $26(39.40 \%)$, similar result observed by Jaffery, et al. study ${ }^{20}$, the M:F ratio was were 2.66:1 (34 vs 16). i.e male have higher incidence than female. In our study it also showed that total male, female was 76 vs 34 . Sex incidence was also higher in Male than female. In different study conducted by Akila, et al. ${ }^{21}$ showed that male are predominance to hypomagnesemia than female and it male female ratio was $5.25: 1$. which supports our study.
Our study have shown serum magnesium in group $A$ and group $B$ was $0.9218 \pm 0.1$ and $0.523 \pm 0.08 \mathrm{mmol} / \mathrm{L}$ respectively. The difference between two groups is statistically significant $(<0.05)$. Other study conducted by Hiralal Murmu ${ }^{19}$, showed the similar result, it was 2.2 $\mathrm{meq} / \mathrm{L}(1.1 \pm 0.175 \mathrm{mmol} / \mathrm{l})$ for control group and $1.01(0.55 \pm 0.07)$ for AMI group. Jaffery, et al. ${ }^{20}$ also showed that mean serum magnesium level was $1.24 \pm 0.48$ but no significant difference in between sex, which supports our study. Whereas Nasim B, et al. ${ }^{8}$, showed mean serum magnesium was $1.7-2.5 \mathrm{meq} /$ $\mathrm{L}(0.85-1.25 \mathrm{mmol} / \mathrm{L})$ on the other hand Chowdhury, et al. ${ }^{18}$ showed it was $0.7 \pm 0.13 \mathrm{mmol} / \mathrm{L}$. In different study conducted by Akila et $\mathrm{al}^{21}$ and it was found serum magnesium level in hypomagnesemia group was $1.65 \pm 0.26 \mathrm{mg} / \mathrm{dl}(0.82 \pm 0.16 \mathrm{mmol} / \mathrm{dl})$.

In our study It has shown that group $B$ patient had significant low $\mathrm{DBP}(\mathrm{mm}-\mathrm{Hg})$ and it was $56.67 \pm 11.56$ (DBP). No such evidence found in any articles regarding this issue.

Akila et, al. ${ }^{21}$ showed smoking, DM, HTN, CVD, Obesity, Dyslipidaemia are risk factors for cardiovascular disease whereas our study shown the similar result which supports our study. In another study conducted by Jaffrey, et al. ${ }^{20}$ showed similar risk factors HTN. Obesity, CVD, DM, Smoking, Dyslipidaemia and Impaired Glucose tolerance test.

Our Study showed raised serum troponin in both group, yet that group $B$ has triple fold rise of serum troponin than that of group $A$. The serum troponin level was $4.7 \pm 0.79 \mathrm{ng} / \mathrm{ml}$ and $14.87 \pm 4.3 \mathrm{ng} / \mathrm{ml}$ in group $A$ and group $B$ respectively. This difference between two groups is statistically significant $(p<0.05)$. It was also observed that raised troponin also associated with severity of hypomagnesemia.

Similarly serum Potassium between two group A and B was $3.84 \pm 0.16$ vs $2.54 \pm 0.41 \mathrm{mmol} / \mathrm{dl}$, The difference between two group was statistically significant $(p<0.05)$. The difference of serum calcium level between two group was statistically significant.

Our study also showed that cardiogenic shock 05(11\%) in group A and $18(27 \%)$ in group B. Group B patient has more shock event than group $A$. The difference between group is statistically significant $(p<0.05)$. Our study also showed ventricular arrhythmia more in group $B$ than group A respectively 15(34\%) vs 48(73\%). The Difference between two groups is statistically significant $(p<0.05)$. Other adverse cardiac events such as asystole, post MI angina, Death were not statistically significant in between 
group. It was observed in our study that hypomagnesemia is positively correlated with ventricular arrhythmia. The study also showed hypokalaemia ,hypocalcaemia and hypomagnesemia also positively correlated with each other.

Our study shows that group B has three times more chance of occurrence of ventricular arrythmia which is 15 vs 48 in between group A vs group $B$. The difference is statistically significant $(p<0.05)$. Similar study found by Hiralal Murmu ${ }^{19}$. He showed that hypomagnesemia group has 2-3 times more chances of ventricular arrythmia than control group which supports our study.

Ceremuynski $\mathrm{L}^{22}$, showed that the mean plasma magnesium concentration was $1.83 \mathrm{mgl} / \mathrm{dl}(0.76 \mathrm{mmol} /$ $\mathrm{L})$ in patient with no abnormal rhythm, $1.68 \mathrm{mg} / \mathrm{dl}(0.7$ $\mathrm{mmol} / \mathrm{L})$ in those with multifocal premature complex and $1.5 \mathrm{mg} / \mathrm{dl}(90.65 \mathrm{mmol} / \mathrm{l})$ in those with unstained ventricular tachycardia. That is hypomagnesemia is positively correlated with occurrence of ventricular arrythmia. Similar results shown by our study which is hypomagnesemia is negatively correlated( $r=-0.543$, $p<0.001$ ) with occurrence of Ventricular arrythmia.

Hiralal Murmu ${ }^{19}$, showed that after Acute myocardial infarction hypomagnesemia occurs within 48hrs in $\operatorname{most}(80 \%)$ cases and which is the causes of ventricular arrythmia. Woods et $\mathrm{al}^{24}$, showed in different study that this ventricular arrythmia improves after IV magnesium infusion. Multivariate logistic regression analysis showed that out of nine variable such as Obesity, SBP, DBP, Heart failure, Cardiogenic shock, Troponin I, Hospital stay, Serum potassium and Serum calcium, none was observed as idependent risk factor for ventricular arrhythmia.

Our study also showed that hypomagnesemia is also associated with hypokalaemia $(r=0.831, p<0.01)$, Multivariate regression analysis strongly disagree hypokalaemia is not independent risk factor for Ventricular arrythmia. Similar study was found by Chowdhury, et al. ${ }^{18}$. In Chowdhury et al ${ }^{18}$ showed that mean level of $\mathrm{Mg}(\mathrm{mmol} / \mathrm{L})$ was $0.59 \pm 0.09$ in group I and $0.67 \pm 0.07$ in group II. The mean level of serum $\mathrm{K}(\mathrm{mmol} /$ L) in group I and group II were $3.28 \pm 0.45$ and $3.63 \pm 0.43$ respectively. Our study showed the similar data. The serum potassium( $\mathrm{mml} / \mathrm{L})$ level in between group $A$ and $B$ respectively $3.84 \pm 0.16$ vs $2.54 \pm 0.41$. This mean difference between group is statistically significant $(p<0.005)$. Similar result supported by Dyckner, et al. ${ }^{24}$ and Kafka, et al. ${ }^{25}$. But no mechanism is yet explained why hypomagnesemia and hypokalaemia occurs concurrently Chowdhury, et al. ${ }^{18}$
Our study showed hypomagnesemia is strongly positively correlated with ventricular arrhythmia and the association was statistically significant. Our study also showed hypomagnesemia is independent variable for developing ventricular arrhythmia.

\section{Conclusion:}

This study showed that there is association of hypomagnesemia and occurrence of ventricular arrythmia in patient with acute myocardial infarction in comparison to normal serum magnesium. It is also showed hypomagnesemia is associated with hypokalaemia and hypocalcaemia, These two mask the hypomagnesemia clinical effects. So it is very difficult to diagnose clinically. Hypomagnesemia patient has bad in hospital prognostic outcome in comparison to normal serum magnesium.

\section{Reference:}

1. Third universal definition of myocardial infarction : European Heart Journal (2012) 33, 2551-2567, doi:10.1093/eurheartj/ehs184

2. Shilpa Patil, Saurabh Gandhi, Piyush Prajapati, Shivraj Afzalpurkar, Omkar Patil, Mohit Khatri. A study of electrolyte imbalance in acute myocardial infarction patients at a tertiary care hospital in western Maharashtra. International Journal of Contemporary Medical Research 2016;3(12):35683571

3. B.Nasim, A. Sajjad, Z. Khan,et al, Prevalence of ACS and Causal Relation of Hypomagnesaemia. British Journal of Medicine \& Medical Research 12(7): 1-5, 2016, Article no.BJMMR.19850,ISSN: 2231-0614, NLM ID: 101570965

4. Antman EM. Magnesium in acute myocardial infarction: overview of available evidence. Am Heart J. 1996;132(2 Pt 2 Su):487-95.

5. Abraham AS, Rosenmann D, Kramer M, Balkin J, Zion MM, Farbstien $\mathrm{H}$, et al. Magnesium in the prevention of lethal arrhythmias in acute myocardial infarction. Arch Intern Med. 1987;147(4):753-5.

6. Shechter M, Kaplinsky E, Rabinowitz B: The rationale of magnesium supplementation in acute myocardial infarction: A review of the literature. Arch Intern Med 1992;1 52:2 189-2 I96

7. R.H. Makoui. Evaluation of Serum Value of Magnesium in Patients with Acute Coronary Syndrome (ACS) and its Relationship with 
Occurrence of Arrhythmias. Middle-East Journal of Scientific Research 12 (8): 1107-1110, 2012, ISSN 1990-9233.

8. B.Nasim, A. Sajjad, Z. Khan, et al, Prevalence of ACS and Causal Relation of Hypomagnesaemia. British Journal of Medicine \& Medical Research 12(7): 1-5, 2016, Article no.BJMMR.19850,ISSN: 2231-0614, NLM ID: 101570965

9. Bernardini, D., A. Nasulewic, A. Mazur and J.A. Majer, 2005. Magnesium and microvascular endothelial cells: a role in inflammation and angiogenesis. Front Biosci, 10: 1177-82.

10. Dr. M.S.Anjum, Dr. S.lqbal, Dr. N. Kalsoom, et al. ACUTE CORONARY SYNDROME; Frequency of hypomagnesaemia in patients. The Profesional Medical Journal Jan-Feb 2013;20(1): 034-038. 034.

11. Abraham AS, Rosenmann D, Kramer M, Balkin J, Zion MM, Farbstien $\mathrm{H}$, et al. Magnesium in the prevention of lethal arrhythmias in acute myocardial infarction. Arch Intern Med. 1987;147(4):753-5.

12. Shechter M, Kaplinsky E, Rabinowitz B: The rationale of magnesium supplementation in acute myocardial infarction: A review of the literature. Arch Intern Med 1992;1 52:2 189-2 196

13. Altura BM, Altura BT: Magnesium ions and contraction of vascu- lar smooth muscles: Relationship to some vascular diseases. Fed Proc 1981 ; 40:2672-2674

14. Vigorito C, Giordano A, Ferraro P, Acanfora D, DeCaprio L, Naddeo C, Rengo F: Hemodynamic effects of magnesium sulfate in the normal human heart .Ain J Curd W/ 1991:67:1435-1437

15. Rabbani LE, Antman EM: Acute myocardial infarction. In Connk Current Therapy, 1993 edition (Ed. Rake1 RE) p 296-3 13. Phila- delphia: W.B. Saunders Company, 1993

16. Casscells W: Magnesium and myocardial infarction. Lancet 1994; 343:807-809
17. Antman EM. Magnesium in acute myocardial infarction: overview of available evidence. Am Heart J. 1996;132(2 Pt 2 Su):487-95.

18. Chowdhury MBK, Rahman M, Hasan M, Begum R, Hoque N., Akhtaruzzaman, M, Chowdhury A. (2011). Dhaka National Medical college Hospital journal, 17(01), pp.33-36.

19. Hiralal Murmu, Lakshman L, (2016). Serum Magnesium in patient with Acute Myocardial Infarction. International Journal of Scientific Study, 4(3), pp.167-169.

20. Jaffery, M., Shaikh, K., Baloch, G. and Sha, S. (2014). Acute myocardial infarction: Hypomagnesemia in patients. The Professional Medical Journal, [online] 21(2), pp.258-263. Available at: http:// www.theprofessional.com [Accessed 31 May 2018].

21. Akhila A, Anandaraj J, Kharthikeyan S: Serum Magnesium level in Acute Myocardial Infarction.IOSR Journal of Medical And Dental Science. May 2017:16(5):35-40.

22. Ceremuynski L, G balska J, Wok R, Makowska E. Hypomagnesemia in heart failure with ventricular arrhythmias. Beneficial effects of magnesium supplementation. J Int Med 2000;247:78-86.

23. Woods K, Fletcher S, Roffe C, Haider Y. (1994). Long-term outcome after intravenous magnesium sulphate in suspected acute myocardial infarction: the second Leicester Intravenous Magnesium Intervention Trial (LIMIT-2). The Lancet, 343(8901), pp.816-819.

24. Dyckner T, Wester PO. Ventricular extrasystoles and intracellular electrolytes before and after potassium and magnesium infusions in patients on diuretic treatment. Am Heart J 1979;97:12-18.

25. Kafka H, Langevin R, Armstrong PW. Serum magnesium and potassium in acute myocardial infarction. Arch Intern Med 1987;147:465-469 